\title{
Acceptance of e-Learning Systems: a Serial Multiple Mediation Analysis
}

\author{
Alexandru Balog \\ National Institute for Research and Development in Informatics - ICI Bucharest, \\ 8-10 Averescu Ave., Bucharest, 011455 Romania \\ alexb@ici.ro
}

\begin{abstract}
The success of an e-learning system depends strongly on understanding the factors that influence students' use and acceptance of this kind of system. Technology acceptance models (TAMs) are frequently used in studies investigating the determinants of adoption and usage of new technologies. Drawing on the findings from extant literature on technology acceptance, this study developed and tested a multiple mediator model using TAM3 framework and concepts. The model was tested on a sample of 220 students using Structural Equation Modeling and serial multiple mediation analysis. The study proved that perceived ease of use and perceived usefulness mediate sequentially the relationships between the four external variables - social influence, facilitating conditions, selfefficacy, perceived enjoyment - and behavioral intention to use the e-learning system . The empirical results provide support for the proposed model. The results indicate that the TAM is a theoretically sound model which can be used to predict students' behavioural intention (BI) to use e-learning systems.
\end{abstract}

Keywords: e-learning acceptance, technology acceptance model, SEM, multiple mediation.

\section{Introduction}

E-learning has become a potential alternative to traditional face-to-face type of learning. It generally refers to the use of computer network technology, primarily over an intranet or through the Internet, to deliver information and instruction to individuals [22]. However, simply providing learners with a web-based learning system does not guarantee a successful e-learning [8]. The success of an e-learning system depends on understanding the factors that influence the students' acceptance of such learning systems. Technology acceptance models and theories are frequently used in studies investigating the determinants of adoption and usage of new technologies.

A well-known model aiming to explain and predict individual adoption and use of information technologies (IT) is Technology Acceptance Model (TAM), developed and validated by Davis [11], and Davis, Bagozzi and Warshaw [12]. TAM has three key variables: perceived usefulness (PU), perceived ease of use (PEOU), and behavioural intention (BI) to use. The two core beliefs, PU and PEOU, are main determinants of an individual's BI to use a technology. The PU and PEOU are influenced by a number of external variables such as user characteristics and system features. TAM further theorizes that the effects of external variables on BI will be mediated by PEOU and PU [12].
The original model was revised and extended with new variables (TAM2 [42], TAM3 [41]) in order to provide a broader view and a better explanation of technologies adoption. The TAM and its subsequent extensions has been applied and tested in many studies, including in e-learning contexts.

However, little research has been done to focus on the actual mediating role of core beliefs and few studies have tested whether PEOU and PU mediate external variables (e.g., [1, 5, 7, 31, 40]). Recent research emphasized that there is limited empirical examination of the social factors, organizational factors, and individual factors that may affect the user adoption and acceptance of e-learning systems [36].

The current research attempts to address the inconsistent findings on mediating role of core beliefs in TAM and to apply advanced statistical methods for inferences about mediated effects. This study investigates acceptance of e-learning systems in Romanian context, using the TAM3 framework. Also, advanced statistical methods (e.g., Structural Equation Modeling, bootstrap method) have been applied within this research.

This study is one of the first attempts to test and prove by advanced methods the mediating role of core beliefs in the technology acceptance models.

The paper is organized as follows. Section 2 briefly reviews theoretical framework. Section 
3 describes the proposed research model and hypotheses, and Section 4 presents research methods. Section 5 shows results, which will be discussed in Section 6. Finally, Section 7 summarizes the main conclusions.

\section{Theoretical Background}

Davis [11] and Davis, Bagozzi \& Warshaw [12] developed the TAM to explain the user's behavioral intention to use information technologies (IT) in the workplace. TAM postulates that individuals' behavioral intention to use IT is determined by the joint action of two core beliefs: Perceived Usefulness (PU) and Perceived Ease of Use (PEOU). PU refers to "the degree to which a person believes that using a particular system leads to increased performance of its activities", while the PEOU is "the degree to which a person expects that using a particular system to be without effort" [12]. In addition, PU is influenced by PEOU while all other influences remain equal, then the easier to use a system, the more useful the system is [11].

It further theorizes that the effects of external variables on intention to use will be mediated by PEOU and PU. The external variables are determinants /antecedents that provide a better understanding of what influences PEOU and PU. As noted by Legris, Ingham \& Collerette [24], their presence guides the actions required to influence a greater use.

TAM has been extensively applied to understanding and explaining users' intention to accept and use a wide range of technological innovations across different users groups in various contexts, including e-learning environments. TAM has also been the subject of several meta-analyses and literature review (e.g., $[24,45,4,18])$.

Many studies extended TAM with additional variables as determinants of TAM core beliefs (see [45], for a review). Venkatesh \& Balla [41] combined the model of determinants of PU, TAM2 model [42] and the model of the determinants of PEOU [40], and developed an integrated model of determinants of individual level IT adoption and use (TAM3). They synthesized previous research on TAM and developed a theoretical framework that identified four different types of determinants of PEOU and PU: individual differences, system characteristics, social influence, and facilitating conditions.

\section{Research Model and Hypotheses}

This study proposes an acceptance model in educational context based on the theoretical framework of TAM3 and the literature review. The model integrates the key constructs of TAM (PU, PEOU, and BI) with antecedents (external variables) found to be important predictors of the key constructs in other technology acceptance studies.

As shown in Figure 1, the model posits that four antecedents will directly influence PEOU and PU. Further, the impact of the antecedents on behavioral intention (BI) to use the elearning system is hypothesized to be fully mediated by PEOU and PU. This specification is taken from TAM, and has been supported by some studies. In addition, the effects of these antecedents on BI to use are sequentially transmitted through PEOU and PU.

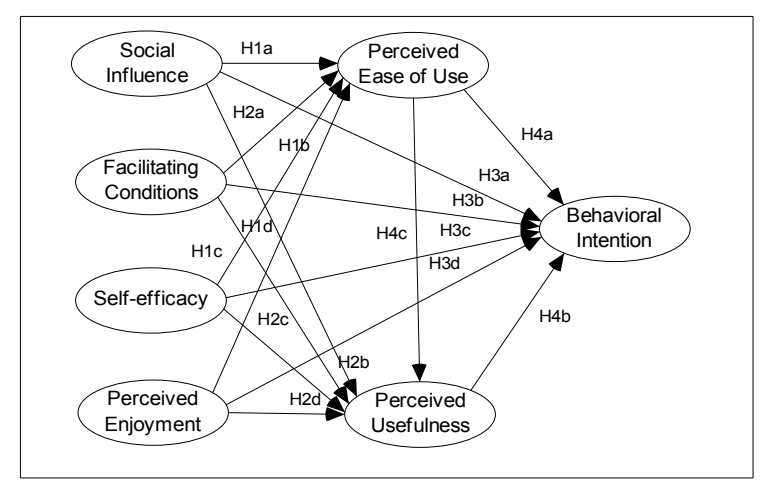

Figure 1. Research model

We discuss the relationships among variables and develop the hypotheses in light of finding from the literature.

Social influence (SI) was defined as the degree to which an individual perceives that important others believe he or she should use the new system [43]. According to Cheng [8] in an elearning context, when individuals perceive that their important referents (e.g., friends, colleagues) think they should use the e-learning system, they will further incorporate the referents' beliefs into their own beliefs. Previous studies revealed that SI is an important antecedent of BI to use ([2, 19, 27, $30]$, an antecedent of PU $([8,19,21,23,39]$, and an antecedent of PEOU [23].

Facilitating conditions (FC) was defined as the degree to which an individual believes that an 
organizational and technical infrastructure exists to support use of the system [41, 43]. In this study, facilitating conditions are the resources (e.g., computers, networks, technical support) in a university that help students perform their tasks and achieve their learning goals. Previous studies showed that organizational support was associated with PEOU and PU [19, 22, 23].

Self-efficacy (SE) reflects one's beliefs about the ability to perform particular tasks successfully. IT researchers have defined computer self-efficacy as self-assessment of individual ability to apply computer skills to complete particular tasks [10]. In this study, SE is interpreted as learner's self-confidence in his or her ability to learn in the e-learning environments. Many studies indicate that individual factors, such as the self-efficacy, have a significant effect on the way that users perceive e-learning systems and, subsequently, on their desire to accept it [8]. In previous studies SE has been shown to influence PEOU $[9,20,23,30,44]$. Also, studies have empirically examined that $\mathrm{SE}$ can be an important factor affecting PU $[29,30]$.

Perceived enjoyment (PENJ) was defined as the extent to which the activity of using a specific system is perceived to be enjoyable in its own right, apart from any performance consequences resulting from system use [40]. Prior research proposed enjoyment as a determinant of behavioural intention [13, 28] and as a determinant of ease of use [40]. In an e-learning context, perceived enjoyment has been shown to influence PEOU and PU [44], and directly BI to use $[8,9]$.

The influence of PEOU on PU in TAM research has been empirically confirmed in literature [13]. There is extensive empirical evidence that PEOU is significantly linked to behavioural intention (BI) to use, both directly and indirectly via its impact on PU [41, 42]. PU has been confirmed in numerous previous studies to be a robust determinant of (BI) to use (e.g., [9, 19, 21, 44]). Almost all of the prior studies tested the effect of PU on BI.

The research model involves testing several sets of hypotheses. The general and specific study hypotheses are as follows.

Hypothesis 1. PEOU of the e-learning system is directly and positively influenced by each of the antecedents in the model.
Specifically, PEOU of the e-learning system is positively influenced by SI (H1a), FC (H1b), SE (H1c), and PENJ (H1d).

Hypothesis 2. PU of the e-learning system is directly and positively influenced by each of the antecedents in the model.

Specifically, PU of the e-learning system is positively influenced by SI (H2a), FC (H2b), $\mathrm{SE}(\mathrm{H} 2 \mathrm{c})$, and PENJ (H2d).

Hypothesis 3. BI to use the e-learning system is directly and positively influenced by each of the antecedents in the model.

Specifically, BI to use the e-learning system is directly and positively influenced by SI (H3a), FC (H3b), SE (H3c), and PENJ (H3d).

Hypothesis 4. BI to use the e-learning system is directly and positively influenced by each of the core beliefs in the model.

Specifically, BI to use the e-learning system is directly and positively influenced by PEOU (H4a) and PU (H4b). Also, PU is directly and positive influenced by PEOU (H4c).

Hypothesis 5. The relationships between BI to use and each of the antecedents are mediated by PEOU.

Specifically, the relationships between BI to use and SI (H5a), FC (H5b), SE (H5c), and PENJ (H5d), are mediated by PEOU.

Hypothesis 6. The relationships between BI to use and each of the antecedents are mediated by PU.

Specifically, the relationships between BI to use and SI (H6a), FC (H6b), SE (H6c), and PENJ (H6d), are mediated by PU.

Hypothesis 7. The relationships between each of the antecedents and BI to use are sequentially mediated by PEOU and PU.

Specifically, the relationships between SI (H7a), FC (H7b), SE (H7c), PENJ (H7d) and $\mathrm{BI}$ to use are sequentially mediated by PEOU and PU.

\section{Methods}

\subsection{Data collection and sample}

The data for this study were obtained by using a questionnaire comprising statements on demographics and multiple items for each variable. All items were measured on a 7-point 
Likert-type scale (1 strongly disagree, 7 strongly agree). The items and the sources from where the items were adapted are presented in Appendix. A total of 220 students from three universities in Romania participated in this study. Of these, $58.2 \%$ were females. The students have used Moodle and WCL v2.7.

\subsection{Analytical procedures}

Data analysis was carried out using the SPSS 16.0 for Windows. Structural Equation Modelling (SEM) with AMOS 7.0 software was applied to test the model. This technique is chosen for its ability to examine a series of dependence relationships simultaneously, especially where there are direct and indirect effects among constructs within model [6]. Testing was carried out in accordance with a two-step approach [3] including measurement and structural models.

\section{Analysis and Results}

\subsection{Descriptive statistics}

All mean scores are greater than 4.0, with a range of 4.87-5.40, indicating that variables were considered important in this study. The standard deviations ranged from 1.005 to 1.172 , indicating a fairly narrow spread of scores around the mean. Both univariate and multivariate outliers were searched in the data set and since none of the cases appeared to be extreme, all the data were kept for analysis. Also, data normality was investigated in terms of skewness and kurtosis. The values were all within the recommended level, supporting the moderate departure from normality for all variables.

\subsection{Measurement model}

The measurement model fits the data well as can be seen in the overall fit indices (Table 1).

We examined the convergent and discriminant validity of the model using the procedure outlined in [14]. The results are shown in Table 2.
Table 1. Goodness of fit indices

\begin{tabular}{|l|l|r|r|}
\hline $\begin{array}{l}\text { Goodnes } \\
\text { s of fit } \\
\text { indices }\end{array}$ & $\begin{array}{l}\text { Recommended } \\
\text { value }^{1}\end{array}$ & $\begin{array}{c}\text { Measurement } \\
\text { model }\end{array}$ & $\begin{array}{c}\text { Structural } \\
\text { model }\end{array}$ \\
\hline$\chi^{2}$ & $\leq 3 \mathrm{df}$ & 467.028 & 476.361 \\
\hline$d f$ & - & 329 & 333 \\
\hline$p$ value & $\mathrm{p}>.05$ & .000 & .000 \\
\hline$\chi^{2} / \mathrm{df}$ & $\leq 3$ & 1.420 & 1.431 \\
\hline TLI & $>.95$ & .955 & .954 \\
\hline CFI & $>.95$ & .961 & .959 \\
\hline SRMR & $\leq .05$ & .048 & .050 \\
\hline $\begin{array}{l}\text { RMSEA, } \\
90 \% \text { CI, }\end{array}$ & $\begin{array}{l}\leq .05 \text { or } \leq .06 \\
\text { close to RMSEA } \\
p \text { value }\end{array}$ & .044 & .044 \\
pclose $>.05$ & {$[.034-.053]$} & {$[.035-.053]$} \\
\hline
\end{tabular}

1 adapted from Byrne [6], Hu \& Bentler [17] and Hair et al. [15]. $\chi^{2}$ : chi-squared; $d f$ : degree of freedom; TLI: TuckerLewis Index; CFI: Comparative Fit Index; SRMR: Standardized Root Mean Square Residual, RMSEA: Root Mean Square Error of Approximation; 90\% CI: 90 Percent Confidence Interval for RMSEA.

Table 2. Results of convergent validity

\begin{tabular}{|c|c|c|c|c|c|c|}
\hline & $\begin{array}{l}\text { Std } \\
\text { load }\end{array}$ & t-value $R 2$ & 2 & $\alpha$ & $\mathrm{CR}$ & AVE \\
\hline \multicolumn{4}{|c|}{ Social Influence (SI) } & 0,862 & 0,871 & 0,634 \\
\hline SI1 & 0,898 & $-{ }^{a}$ & 0,806 & & & \\
\hline SI2 & 0,873 & 17,454 & 0,761 & & & \\
\hline SI3 & 0,805 & 15,245 & 0,648 & & & \\
\hline SI4 & 0,566 & $5 \quad 9,091$ & 0,321 & & & \\
\hline \multicolumn{4}{|c|}{ Facilitating Conditions (FC) } & 0,763 & 0,778 & 0,479 \\
\hline FC1 & 0,753 & $3 \quad-\mathrm{a}$ & 0,567 & & & \\
\hline $\mathrm{FC} 2$ & 0,753 & 10,119 & 0,567 & & & \\
\hline FC3 & 0,778 & 10,376 & 0,606 & & & \\
\hline FC4 & 0,420 & 5,704 & 0,176 & & & \\
\hline \multicolumn{4}{|c|}{ Self-efficacy (SE) } & 0,889 & 0,892 & 0,674 \\
\hline SE1 & 0,797 & $-{ }^{a}$ & 0,635 & & & \\
\hline SE2 & 0,853 & 14,002 & 0,728 & & & \\
\hline SE3 & 0,755 & 12,000 & 0,570 & & & \\
\hline SE4 & 0,873 & 314,398 & 0,763 & & & \\
\hline \multicolumn{4}{|c|}{ Perceived Enjoyment (PENJ) } & 0,851 & 0,853 & 0,592 \\
\hline ENJ1 & 0,816 & $5 \quad-{ }^{a}$ & 0,666 & & & \\
\hline ENJ2 & 0,803 & 12,610 & 0,646 & & & \\
\hline ENJ3 & 0,736 & 11,393 & 0,542 & & & \\
\hline ENJ4 & 0,718 & 11,050 & 0,515 & & & \\
\hline \multicolumn{4}{|c|}{ Perceived Ease of Use (PEOU) } & 0,836 & 0,841 & 0,575 \\
\hline PEOU1 & 0,833 & $-a^{a}$ & 0,693 & & & \\
\hline PEOU2 & 0,644 & 10,184 & 0,415 & & & \\
\hline PEOU3 & 0,891 & 15,622 & 0,794 & & & \\
\hline PEOU6 & 0,631 & 9,930 & 0,398 & & & \\
\hline \multicolumn{4}{|c|}{ Perceived Usefulness (PU) } & 0,868 & 0,876 & 0,593 \\
\hline PU1 & 0,841 & $-{ }^{a}$ & 0,708 & & & \\
\hline PU2 & 0,848 & 15,199 & 0,718 & & & \\
\hline PU3 & 0,809 & 14,178 & 0,655 & & & \\
\hline PU4 & 0,793 & 13,769 & 0,629 & & & \\
\hline PU5 & 0,505 & 7,689 & 0,255 & & & \\
\hline \multicolumn{5}{|c|}{ Behavioural Intention to Use (BI) 0,729} & 0,759 & 0,530 \\
\hline BI1 & 0,427 & $-{ }^{\mathrm{a}}$ & 0,182 & & & \\
\hline BI2 & 0,853 & 6,166 & 0,727 & & & \\
\hline $\mathrm{BI} 3$ & 0,825 & 6,126 & 0,681 & & & \\
\hline
\end{tabular}

${ }^{\mathrm{a}}$ Indicates a parameter fixed at 1.0 in the original solution 
As shown in Table 2, all standardized item loading were statistically significant (t-values $>$ 1.96), and ranged from 0.420 to 0.898 . With the exception for FC4 and BI1, other factor loading were above the minimally acceptable threshold of 0,50 . With few exceptions, the item reliability (R2) values are above the suggested standard of 0,50 [15].

According to Table 2, the Cronbach's alpha values ranged from 0,729 to 0,889 , and the composite reliability $(\mathrm{CR})$ values ranged from 0.759 to 0.892 These values are above the minimum level of 0.70 [15], indicating an adequate reliability. The values of average variance extracted (AVE) are all above the minimum level of 0.50 [15], ranging from 0.530 to 0.674 , except for FC (0.479), confirming convergent validity.

The discriminant validity of constructs was examined through the squared correlations test [14]. The results in Table 3 show that the square root of the AVE for each construct is greater than the correlations involving the construct thus provides evidence of adequate discriminant validity.

Table 3. Results of discriminant validity

\begin{tabular}{llllllll}
\hline & SI & FC & SE & PENJ & PEOU & PU & BI \\
\hline SI & $\mathbf{0 , 8 0}$ & & & & & & \\
FC & 0,57 & $\mathbf{0 , 6 9}$ & & & & & \\
SE & 0,49 & 0,45 & $\mathbf{0 , 8 2}$ & & & & \\
PENJ & 0,56 & 0,49 & 0,56 & $\mathbf{0 , 7 7}$ & & & \\
PEOU & 0,64 & 0,60 & 0,69 & 0,65 & $\mathbf{0 , 7 6}$ & & \\
PU & 0,62 & 0,59 & 0,62 & 0,63 & 0,72 & $\mathbf{0 , 7 7}$ & \\
BI & 0,67 & 0,55 & 0,60 & 0,62 & 0,74 & 0,74 & $\mathbf{0 , 7 3}$ \\
\hline
\end{tabular}

Notes: The bold diagonal numbers are the square root of AVE

\subsection{Structural model}

With adequate psychometric properties in the measurement model, the structural model was examined. SEM with AMOS 7 was performed to identify the links between variables and to test the hypotheses. As shown in Table 1, all the overall fit indices suggested a good fit.

The standardized path coefficients and their significance (see Figure 2) show that all hypothesized relationships between the antecedents and the core beliefs ( $\mathrm{H} 1$ and $\mathrm{H} 2)$, and between the core beliefs and $\mathrm{BI}$ to use $(\mathrm{H} 4 \mathrm{a}$, $\mathrm{H} 4 \mathrm{~b}$ ), and between the core beliefs ( $\mathrm{H} 4 \mathrm{c})$ were statistically significant at or above the $95 \%$ confidence level. Regarding the influence of the antecedents on BI to use, H3a was supported, while $\mathrm{H} 3 \mathrm{~b}, \mathrm{H} 3 \mathrm{c}$ and $\mathrm{H} 3 \mathrm{~d}$ were not supported.
The explained variances (R2) of PEOU, PU and BI show a good predictive validity.

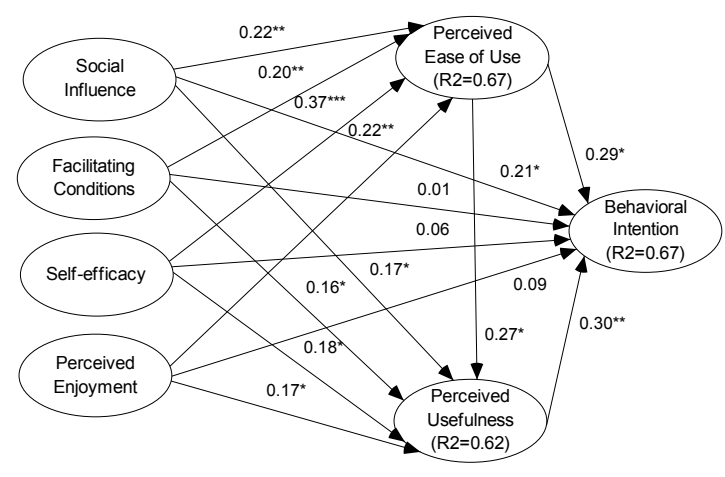

Note: $* \mathrm{p}<.05 ; * * \mathrm{p}<.01 ; * * * \mathrm{p}<.001$.

Figure 2. Path estimates and explained variances

\subsection{Mediation effects}

In this study, the author tested a three-path mediated effect [37]. The advantage of this approach is that we were able to isolate the indirect effects of both mediators, PEOU and PU. This approach also allowed us to investigate the indirect effect passing through both of these mediators in a series.

Mediating effects were tested by procedures developed by Hayes [16] and Preacher \& Hayes [32]. Many researchers [25, 32, 34, 35] recommended and advocated using bootstrapping method as a robust means for assessing significance of the indirect effects. This study used bootstrapping for obtaining asymmetrical confidence limits for indirect effects. Specifically, it used 5.000 bootstrap resamples to generate $95 \%$ bias-corrected confidence intervals for the indirect effects. According to [16], the indirect effects are reported in unstandardized form.

First, the significant parameter estimates were found for indirect effects of the antecedents on PU through PEOU, on BI through PU, and on BI through both PEOU and PU. The all the specific indirect effects through the each of mediators were found significant, because zero is not included in the $95 \%$ confidence interval. Therefore, the general hypotheses H5 and H6 are supported.

Moreover, following the suggestions of Preacher \& Kelly [33] and the online calculator (http://stats.myresearch survey.com /kappasquared) provided by Ian Rothmann, the kappa squared (k2), which is a new and robust effect size measure for mediation models, was computed in order to examine the importance of 
the mediating role of PEOU and PU. As recommended by authors, the $\mathrm{k} 2$ measure can be interpreted using Cohen's guidelines defining small $(0,01)$, medium $(0,09)$ and large $(0,25)$ effect size. For example, as shown in Table 4, for $\mathrm{SE} \rightarrow \mathrm{PEOU} \rightarrow \mathrm{BI}$ the estimate of $\mathrm{k}^{2}$ was 0.097 and can be interpreted as a medium effect size. For all the other mediated relationships, the mediating effect size was small.

Table 4. Specific indirect effects and effect size

\begin{tabular}{|c|c|c|c|}
\hline Нур. & Path & Value $\left.^{*}\right)$ & Effect size $\left.^{* *}\right)$ \\
\hline $\mathrm{H} 5 \mathrm{a}$ & $\mathrm{SI} \rightarrow \mathrm{PEOU} \rightarrow \mathrm{BI}$ & 0,028 & 0.066 \\
\hline $\mathrm{H} 5 \mathrm{~b}$ & $\mathrm{FC} \rightarrow \mathrm{PEOU} \rightarrow \mathrm{BI}$ & 0,031 & 0,057 \\
\hline $\mathrm{H} 5 \mathrm{c}$ & $\mathrm{SE} \rightarrow \mathrm{PEOU} \rightarrow \mathrm{BI}$ & 0,049 & 0,097 \\
\hline H5d & $\mathrm{PENJ} \rightarrow \mathrm{PEOU} \rightarrow \mathrm{BI}$ & 0,032 & 0,062 \\
\hline H6a & $\mathrm{SI} \rightarrow \mathrm{PU} \rightarrow \mathrm{BI}$ & 0,023 & 0,055 \\
\hline $\mathrm{H} 6 \mathrm{~b}$ & $\mathrm{FC} \rightarrow \mathrm{PU} \rightarrow \mathrm{BI}$ & 0,026 & 0,049 \\
\hline H6c & $\mathrm{SE} \rightarrow \mathrm{PU} \rightarrow \mathrm{BI}$ & 0,025 & 0,055 \\
\hline H6d & $\mathrm{PENJ} \rightarrow \mathrm{PU} \rightarrow \mathrm{BI}$ & 0,027 & 0,052 \\
\hline $\mathrm{H} 7 \mathrm{a}$ & $\mathrm{SI} \rightarrow \mathrm{PEOU} \rightarrow \mathrm{PU} \rightarrow \mathrm{BI}$ & 0,008 & - \\
\hline $\mathrm{H} 7 \mathrm{~b}$ & $\mathrm{FC} \rightarrow \mathrm{PEOU} \rightarrow \mathrm{PU} \rightarrow \mathrm{BI}$ & 0,009 & - \\
\hline $\mathrm{H} 7 \mathrm{c}$ & $\mathrm{SE} \rightarrow \mathrm{PEOU} \rightarrow \mathrm{PU} \rightarrow \mathrm{BI}$ & 0,014 & - \\
\hline H7d & $\mathrm{PENJ} \rightarrow \mathrm{PEOU} \rightarrow \mathrm{PU} \rightarrow \mathrm{BI}$ & 0,009 & - \\
\hline
\end{tabular}

*) unstandardized values; **) k2 only for a single mediator

Second, Table 5 shows that the all the total indirect effects of the antecedents on BI to use are sequentially mediated by PEOU and PU. None of the confidence intervals included zero, so the general hypothesis of mediation (H7) was suported. For example, the total indirect effect of social influence (SI) through both PEOU and PU was found significant with point estimate of 0,060 and the $95 \%$ confidence interval $(0,025-0,121)$ did not include zero.

Table 5. Total indirect effects

\begin{tabular}{|c|c|c|c|c|}
\hline & \multirow[b]{2}{*}{ Effect } & \multicolumn{3}{|c|}{ Bias-corrected bootstrap } \\
\hline & & $\begin{array}{l}\text { Lower } \\
\text { Bounds }\end{array}$ & $\begin{array}{l}\text { Upper } \\
\text { Bounds }\end{array}$ & $\mathrm{P}$ \\
\hline BI-PU-PEOU-SI & 0,060 & 0,025 & 0,121 & 0,000 \\
\hline BI-PU-PEOU-FC & 0,066 & 0,025 & 0,141 & 0,001 \\
\hline BI-PU-PEOU-SE & 0,088 & 0,041 & 0,163 & 0,000 \\
\hline BI-PU-PEOU-PENJ & 0,068 & 0,026 & 0,143 & 0,000 \\
\hline
\end{tabular}

Third, it is of interest to investigate whether the two indirect effects differ significantly. By applying the equations suggested in $[16,26]$, examination of the contrast shown that the specific indirect effects through PEOU are larger than the specific indirect effects through PU, for all the mediated relationships. However, calculations of all possible pairwise comparisons between specific indirect effects have shown mixed results regarding of the significant differences.
Finally, it should be noted that the direct link between social influence and BI was found to be significant, indicating that the effect of SI on $\mathrm{BI}$ is partially mediated by PEOU and PU. The direct effect of other antecedents (FC, SE, and PENJ) was found to be non-significant, indicating that these relationships are fully mediated by PEOU and PU.

\section{Discussion}

Overall, the proposed model demonstrated good fit with the sample data. Further, twentyfour of the twenty-seven specific hypotheses were found to be significant.

This study was found that both PEOU and PU are important factors in determining the acceptance of e-learning systems. The effect of PEOU on PU in TAM research has been empirically confirmed in literature. If elearning systems are perceived to be easy of use, students may perceive them as being useful. This finding supports existing studies showing a strong relationship between PEOU and PU, as proposed by Davis et. al. [12].

The findings of this study show that all the external variables influenced positively and significantly core beliefs, but their influence on PEOU are all higher than their influence on PU. The results indicated that self-efficacy was the strongest antecedent which influenced PEOU and PU $(\beta=0.37, t$-value $=5.18 ; \beta=0.18, t$ value $=2.28$, respectively), followed by social influence $(\beta=0.22, t$-value $=3.05$ and $\beta=0.17, t$ value $=2.24)$, perceived enjoyment $(\beta=0.22, t$ value $=2.90$ and $\beta=0.17, t$-value $=2.15)$, and facilitating conditions $(\beta=0.20, t$-value $=2.74$ and $\beta=0.16, t$-value $=2.06$ ).

In addition to having direct effects, the antecedents also have indirect effects on PU and BI. Therefore, PEOU and PU may function as mediators in the relationships between the antecedents and $\mathrm{BI}$.

Self-efficacy has positive effects on students' PEOU and PU of e-learning systems. Students who were highly confident in their computer skills were more likely to perceive e-learning systems as being easy to use and usefulness, which, in turn, led to higher BIs to use elearning systems. The finding is also supported by the previous studies (e.g., [9, 21, 23, 42, 44]).

This study shows the social influence is significantly associated with PEOU and PU and 
in turn related to BI to use. The students are influenced by the colleagues, and thus they believe the e-learning system must be useful in its purpose, and further intend to use it. This finding is consistent with several prior studies (e.g., $[2,8,27])$.

This study found that perceived enjoyment is a important antecedent of PEOU and PU, suggesting that an enjoyable learning experience is increasing the ease of use and the usefulness, and further BI to use the e-learning system. This finding is consistent with several prior studies (e.g., [8, 9, 44]).

While facilitating conditions (FC) did not have much direct effect on BI, FC had small indirect effect on BI, suggesting that FC had a more effective influence on BI when it was mediated by PEOU and PU. FC had a significant influence on PEOU and PU. This suggests that when students perceived an adequate level of support (e.g., technical support), they tend to view technology as an easy to use and usefulness tool.

This study was found that the relationships between BI to use and the each of the antecedents are mediated by each of the core beliefs (PEOU and PU). Furthermore, the relationships between the each of the antecedents and BI to use are sequentially mediated by PEOU and PU.

As noted by Venkatesh \& Balla [41], TAM consistently explains about $40 \%$ of the variance in individuals intention to use an IT, and TAM3 explained between $40 \%$ and $53 \%$ variance in behavioral intention. In this study, $67 \%$ of the variance of BI to use the e-learning system can be considered very good.

The results indicate that the proposed model is a theoretically sound model which can be used to predict students' behavioral intention to use e-learning systems. By applying the proposed model, this study may help practitioners and researchers to understand better the antecedents of PEOU and PU in e-learning environments.

\section{Conclusions}

The objective of this study is to contribute to the improvement of models of technology acceptance. Drawing on the findings from extant literature on technology acceptance, this study developed and tested a multiple mediator model using the TAM3 framework and concepts. The study proves that relationships between behavioral intention to use and the each of the antecedents - social influence, facilitating conditions, self-efficacy, perceived enjoyment - are mediated by the perceived ease of use and perceived usefulness. The empirical results provide support for the proposed model.

As noted by Pituch \& Lee [31], whereas some researchers have found that core beliefs fully mediate the relationships between external factors and technology use, other researchers have found direct effects between such external factors and technology use.

There are inherent limitations of this research that should suggest some research directions. Firstly, while this study has been conducted with methodological rigour, the findings should be used with caution. Since this study only examines the acceptance of e-learning system using a convenience sample from Romania, the results may not be generalised to other systems and cultures. Secondly, as the study was crosssectional, it was not possible to establish a causal model explaining the above-mentioned relationships. Longitudinal design could be employed to examine these relationships and to reach more valid conclusions.

Despite its limitations, this study has value as its findings provided several theoretical and practical implications. In the development and validation of the theories of educational technology acceptance, researchers should take into consideration individual, social, and organizational factors. When implementing elearning systems it is important to focus on usefulness and ease of use. Finally, in the selection of potential e-learning systems it is advisable to prioritise external factors.

\section{Acknowledgements}

This research was partially supported by the ANCS, contract no. 12090/2007.

\section{REFERENCES}

1. AGARWAL, R., J. PRASAD, Are Individual Differences Germane to the Acceptance of New Information Technologies? Decision Science vol. 30, no. 2, 1999, pp. 361-391.

2. AGUDO-PEREGRINA, A. F., A. HERNANDEZ-GARCIA, F. J. PASCUALMIGUEL, Behavioral Intention, Use 
Behavior and the Acceptance of Electronic Learning Systems: Differences between Higher Education and Lifelong Learning. Computer in Human Behavior vol. 34, 204, pp. 301-314.

3. ANDERSON, J. C., D. W. GERBING, Structural Equation Modeling in Practice: A Review and Recommended Two-step Approach. Psychological Bulletin., vol. 103, no. 3, 1988, pp. 411423.

4. BANCIU, D., A. BALOG, Calitatea sistemelor si serviciilor de e-learning. Editura AGIR, Bucuresti, 2013.

5. BURTON-JONES, A., G. S. HUBONA, The Mediation of External Variables in the Technology Acceptance Model. Information \& Management, vol. 43, no. 6, 2006, pp. 706-717.

6. BYRNE, B., Structural Equation Modeling with AMOS. Basic Concepts, Applications, and Programming. Lawrence Erlbaum Ass. Publishers 2001.

7. CHEN, H. R., H. F. TSENG, Factors that Influence Acceptance of Web-based eLearning Systems for the In-service Education of Junior High School Teachers in Taiwan. Evaluation and Program Planning vol. 35, 2012, pp.398-406.

8. CHENG, Y. M. Antecedents and Consequences of e-Learning Acceptance. Information System Journal vol. 21, no. 3, 2011, pp. 269-299.

9. CHIU, C. M., E. T. G. WANG, Understanding Web-based Learning Continuance Intention: The Role of Subjective Task Value. Information and Management, vol. 45(3), 2008, pp. 194-201.

10. COMPEAU, D. R., C. A. HIGGINS, Computer Self-efficacy: Development of a Measure and Initial Test. MIS Quarterly, vol. 19, no.2, 1995, pp. 189-211.

11. DAVIS, F. D. Perceived Usefulness, Perceived Ease of Use, and User Acceptance of Information Technology. MIS Quarterly, vol. 13(3), 1989, pp. 319-340.

12. DAVIS, F. D., R. P. BAGOZZI, P. R. WARSHAW, User Acceptance of Computer Technology: A Comparison of Two Theoretical Models. Management Sci., vol. 35 , no. 8,1989 , pp. 982-1003.
13. DAVIS, F. D., R. P. BAGOZZI, P. R. WARSHAW, Extrinsic and Intrinsic Motivation to Use Computers in the Workplace. Journal of Applied Social Psychology, vol. 22, no. 14, 1992, pp. 1111-1132.

14. FORNELL, C., D. F. LARCKER, Evaluating Structural Equations Models with Unobservable Variables and Measurement Error. Journal of Marketing Research, vol. 18(1), 1981, pp. 39-50.

15. HAIR, J. F., W. C. BLACK, B. J. BABIN, R. E. ANDERSON, R. L. TATHAM, Multivariate Data Analysis. $6^{\text {th }}$ ed., Prentice Hall, 2006.

16. HAYES, A. Introduction to Mediation, Moderation, and Conditional Process Analysis: a Regression based Approach. Guilford Press, New York, 2013.

17. HU, L. T., P. M. BENTLER, Cutoff Criteria for Fit Indexes in Covariance Structure Analysis: Conventional Criteria Versus New Alternatives. Structural Equation Modeling vol. 6, no. 1, 1999, pp. 1-55.

18. IORDACHE, D. D. Modele de acceptare a tehnologiilor în e-learning. Revista Română de Interacțiune Om Calculator, vol. 3(2), 2010, pp. 125-138.

19. KARAALI, D., C. A. GUMUSSOY, F. CALISIR, Factors Affecting the Intention to Use a Web-based Learning System among Blue-collar Workers in the Automotive Industry. Computer in Human Behavior, vol. 27(1), 2011, pp. 343-354.

20. KIM, B. G., S. C. PARK, K. L., LEE, A Structural Equation Modeling of the Internet Acceptance in Korea. Electronic Commerce Research and Applications, vol. 6, 2007, pp. 425-432.

21. LEE, Y. H. An Empirical Investigation into Factors Influencing the Adoption of an e-Learning System. Online Info. Review, vol. 30, no. 5, 2006, pp. 517-541.

22. LEE, Y. H., Y. C. HSIEH, Y. H. CHEN, An Investigating of Employees' Use of eLearning Systems: Applying the Technology Acceptance Model. Behavioral \& Information Technology, vol. 32, no. 2, 2013, pp. 173-189. 
23. LEE, Y. H., Y. C. HSIEH, C. Y. MA, A Model of Organizational Employees' eLearning Systems Acceptance. KnowledgeBased Systems 24, 2011, pp. 355-366.

24. LEGRIS, P., J. INGHAM, P. COLLERETTE, Why Do People Use Information Technology? A Critical Review of the Technology Acceptance Model. Information and Management, vol. 40(3), 2003, pp. 191-204.

25. MACKINNON, D. P. Introduction to Statistical Mediation Analysis. Erlbaum Psych Press, New York. 2008.

26. MACKINNON, D. P., C. M. LOCKWOOD, J. WILLIAMS, Confidence Limits for the Indirect Effect: Distribution of the Product and Resampling Methods. Multivariate Behavioral Research vol. 39(1), 2004, pp. 99-128.

27. MALDONADO, U. P. T., G. F. KHAN, J. MOON, J. J. RHO, E-Learning Motivation and Educational Portal Acceptance in Developing Countries. Online Info. Review, vol.35, no.1, 2011, pp. 66-85.

28. NICULESCU, A., G. THORSTEINSSON, Enabling Idea Generation through Computer-Assisted Collaborative Learning. Studies in Informatics and Control, vol. 20(4), 2011, pp. 403-410.

29. ONG, C., J. LAI, Gender Differences in Perceptions and Relationships among Dominants of e-Learning Acceptance. Computers in Human Behavior, vol. 22, no. 5, 2006, pp. 816-829.

30. PARK, S. Y. An Analysis of the Technology Acceptance Model in Understanding University Students' Behavioral Intention to Use e-Learning. Educational Technology \& Society, vol. 12(3), 2009, pp. 150-162.

31. PITUCH, K. A., Y. K. LEE, The Influence of System Characteristics on e-Learning Use. Computer \& Education vol. 47, 2006, pp. 222-244.

32. PREACHER, K. J., A. F. HAYES, Asymptotic and Resampling Strategies for Assessing and Comparing Indirect Effects in Multiple Mediator Models. Behavior Research Methods vol. 40(3), 2008, pp. 879-891.
33. PREACHER, K. J., K. KELLY, Effect Size Measures for Mediation Models: Quantitative Strategies for Communicating Indirect Effects. Psychological Methods, vol. 16(2), 2011, pp. 93-115.

34. RUNGTUSANATHAM, M., J. W. MILLER, K. K. BOYER, Theorizing, Testing, and Concluding for Mediation in SCM Research: Tutorial and Procedural Recommendations. Journal of Operations Management vol. 32, 2014, pp. 99-113.

35. SHROUT, P. E., N. BOLGER, Mediation in Experimental and Non Experimental Studies: New Procedures and Recommendations. Psychological Methods, vol. 7, no. 4, 2002, pp. 422-445.

36. TARHINI, A., K. HONE, X. LIU, User Acceptance Towards Web-based Learning Systems: Investigating the Role of Social, Organizational and Individual Factors in European Higher Education. Procedia Computer Science, vol. 17, pp. 189-197.

37. TAYLOR, A. B., D. P. MACKINNON, J. Y. TEIN, Tests of the Three-path Mediated Effect. Organizational Research Methods vol. 11, no. 2, 2008, pp. 241-269.

38. TEO, T. Examining the Intention to Use Technology among Pre-Service Teachers: an Integration of the Technology Acceptance Model and Theory of Planned Behavior. Interactive Learning Environments vol. 20(1), 2012, pp. 3-18.

39. VAN RAAIJ, E. M., J. J. L. SCHEPERS, The Acceptance and Use of a Virtual Learning Environment in China. Computers \& Education, vol. 50(3), 2008, pp. 838-852.

40. VENKATESH, V. Determinants of Perceived Ease of Use: Integrating Control, Intrinsic Motivation, and Emotion into the Technology Acceptance Model. Information Systems Research, vol. 11 , no. 4, 2000, pp. 342-365.

41. VENKATESH, V., H. BALA, Technology Acceptance Model 3 and a Research Agenda on Interventions. Decision Science, vol. 39, no. 2, 2008, pp. 273-315.

42. VENKATESH, V., F. D. DAVIS, A Theoretical Extension of the Technology Acceptance Model: Four Longitudinal Field Studies. Management Science, vol. 45, no. 2, 2000, pp. 186-204. 
43. VENKATESH, V., M. MORRIS, G. DAVIS, F. DAVIS, User Acceptance of Information Technology: Toward a Unified View. MIS Quarterly vol. 27, no. 3, 2003, pp. 425-478.

\section{YI, M. Y., Y. HWANG, Predicting the Use of Web-based Information Systems: Self- efficacy, Enjoyment, Learning Goal Orientation, and the Technology}

Acceptance Model, International Journal of Human Computer Studies, vol. 59, no. 4, 2003, pp. 431-449.

45. YOUSAFZAI, S. Y., G. R. FOXALL, J. G. PALLISTER, Technology Acceptance: a Meta-analysis of the TAM. Journal of Modelling and Management, vol. 2(3), 2007, pp. 251-280.

\section{Appendix 1 List of items and sources}

\begin{tabular}{|c|c|c|}
\hline \multicolumn{3}{|c|}{ Constructs / Code / Items $\quad$ Description } \\
\hline \multicolumn{3}{|c|}{ Perceived Usefulness } \\
\hline PU1 & Using the e-learning system will allow me to accomplish learning tasks more quickly & \multirow{4}{*}{$\begin{array}{l}\text { Davis, 1989; Venkatesh et } \\
\text { al., 003; Pituch \& Lee, } \\
\text { 2006; Chiu \& Wang, 2008; } \\
\text { Cheng, 2011; }\end{array}$} \\
\hline PU2 & Using the e-learning system will improve my learning performance & \\
\hline PU4 & Using the e-learning system will enhance my effectiveness in learning & \\
\hline PU5 & I find the e-learning system useful in my learning & \\
\hline \multicolumn{3}{|c|}{ Perceived Ease of Use } \\
\hline PEOU3 & My interaction with the e-learning system is clear and understandable & \multirow{2}{*}{$\begin{array}{l}\text { Davis, 1989; Venkatesh et } \\
\text { al., 003; Pituch \& Lee, } \\
\text { 2006; Chiu \& Wang, 2008; }\end{array}$} \\
\hline PEOU6 & I find the e-learning system to be easy to use & \\
\hline \multicolumn{3}{|c|}{ Social Influence } \\
\hline SI1 & People who influence my behavior think that I should use the e-learning system & \multirow{2}{*}{$\begin{array}{l}\text { Venkatesh et al., } 2003 \text { Chiu } \\
\text { \& Wang, 2008; }\end{array}$} \\
\hline SI2 & People who are important to me think that I should use the e-learning system & \\
\hline FC2 & I have the knowledge necessary to use the $\mathrm{v}$ & \multirow{3}{*}{$\begin{array}{l}\text { Venkatesh et al., 003; Chiu } \\
\text { \& Wang, 2008; }\end{array}$} \\
\hline FC3 & The e-learning system is compatible with other systems I use & \\
\hline $\mathrm{FC} 4$ & A specific person (or group) is available for assistance with system difficulties & \\
\hline \multicolumn{3}{|c|}{ Self-efficacy $\quad$ I could complete my learning activities using the e-learning system } \\
\hline SE1 & Even if there is no one around to show me how to do it & \multirow{4}{*}{$\begin{array}{l}\text { Pituch \& Lee, 2006; Chiu } \\
\text { \& Wang, 2008; Cheng, } \\
\text { 2011; Compeau-Higgins } \\
\text { 1995; }\end{array}$} \\
\hline SE2 & Even if I have only the online instructions for reference & \\
\hline SE3 & Even if I had never used such a system before & \\
\hline SE4 & If I had seen someone else using it before trying it myself & \\
\hline \multicolumn{3}{|c|}{ Perceived Enjoyment } \\
\hline ENJ1 & I think using the e-learning system is enjoyable & \multirow{3}{*}{$\begin{array}{l}\text { Davis et al., 1992; } \\
\text { Venkatesh-Bala, 2008; } \\
\text { Cheng, 2011; }\end{array}$} \\
\hline ENJ2 & I think using the e-learning system is exciting & \\
\hline ENJ3 & I think using the e-learning system is fun & \\
\hline \multicolumn{3}{|c|}{ Behavioral Intention to Use } \\
\hline BI1 & If I could, I would like to continue using the e-learning system in my activities in the future & \multirow[t]{3}{*}{ Chiu \& Wang, 2008; } \\
\hline $\mathrm{BI} 2$ & It is likely that I will continue using the e-learning system in the future. & \\
\hline $\mathrm{BI} 3$ & I expect to continue using the e-learning system in the future & \\
\hline
\end{tabular}

